\title{
Interruption of the Middle Cerebral Artery in 10-Day-Old Rat Alters Normal Development of Distal Collaterals
}

\author{
PETER COYLE \\ Department of Anatomy and Cell Biology, The University of Michigan Medical School, \\ Ann Arbor, MI 48109
}

\begin{abstract}
Pial surface arterioles join rami of the anterior and middle cerebral arteries (MCA) in 10-day-old normal Wistar rats. Normally, the anastomosing branches differentiate into small-diameter vessels with significantly greater tortuosity (length) by 56 days of age. After interruption of the MCA in 10-day-old rats, large-diameter, relatively straight collaterals were observed 46 or $90-110$ days later. Evidently altered hemodynamic factors, as the result of MCA interruption, prevent the development of a normal pattern of arterioles and augment the development of an anomalous pattern of collaterals in young Wistar rats.
\end{abstract}

A prior study indicated that distal branches of the anterior (ACA) and middle (MCA) cerebral arteries are joined by collaterals in the 5-6-week-old normal Wistar (NW) rat (Coyle and Jokelainen, 1982). A method was developed to occlude the MCA in the rat (Coyle, 1982). Twenty days after rapid occlusion of the MCA, the diameters and lengths of these collaterals were increased, but there was no evidence that new vessels were formed (Coyle, 1984). The expanded collaterals provided blood supply that usually protected the MCA tissue field from infarction (Coyle, 1982; Coyle and Jokelainen, 1983; Coyle et al., 1984).

The purpose of this study was to investigate the collateral expansion initiated prior to termination of cellular proliferation in capillary beds and the developing cerebral cortex (Craigie, 1925, 1955; Caley and Maxwell, 1971; Rowan and Maxwell, 1981). Objectives were to determine whether or not and, if so, to what extent the natural development of the collaterals was altered by vessel interruption at an early age.

\section{MATERIALS AND METHODS}

\section{Surgery and Vessel Preparations}

Six 10-day-old NW rats, including members of each sex, were anesthetized with ketamine hydrochloride (1$2.5 \mathrm{mg}$ ) intramuscularly. Details of the surgery and equipment necessary to expose the MCA through craniectomy are stated elsewhere (Coyle, 1982). The MCA was transected dorsal to the rhinal fissure with iridectomy scissors. Hemorrhage was not a problem, and the cranial wound was closed with silk suture. The pup was returned to its dam and litter mates. No more than two pups were taken from the same litter. Cannibalism did not occur.

At 56 (or between 100-120) days of age, rats with the MCA occluded when 10 days old and five unoperated controls were anesthetized with ether and received papaverine hydrochloride (40-50 $\mathrm{mg} / \mathrm{kg}$ body wt) intravenously for maximum dilation of vessels prior to injection of Vultex (Chicago Latex Products No. 563). Five 10-dayold rats were anesthetized, and the latex was injected via a hypodermic needle inserted through the left ventricle into the ascending aorta. Visual inspection of the dorsal collaterals during the filling period prevented overfilling and bursting of the vessels. Controls for other potential problems associated with vessel occlusion, identification of unfilled vessel patterns, standardization of vessel diameters with papaverine, and vessel pattern asymmetries were discussed in detail elsewhere in this journal (Coyle, 1984). Brains were stored in $10 \%$ neutral buffered formalin prior to photography.

\section{MEASUREMENTS AND COMPUTATIONS}

Dorsal collaterals join distal branches of the ACA and MCA. Characteristically the branch angle of an ACA ramus faces the branch angle of the anastomosing MCA ramus (Fig. 1). Often, although not invariably, two distal rami of an ACA branch join in end-to-end anastomoses with two distal rami of an MCA branch. The shape of the end-to-end vascular complex is roughly that of a diamond. Common variations of this collateral unit include vascular complexes with end-to-side or side-toside configurations where one end, or a side branch, is a collateral (Fig. 1).

Coordinates $(\mathrm{x}, \mathrm{y})$ of about 70 points located along the side of a collateral were sampled from a photograph with a Summagraphics Corporation Bit Pad interfaced to a Commodore Microcomputer (Coyle, 1981). Vessel segment distance between adjacent sample points was computed as the hypotenuse of a right triangle, and the vessel length (VL) was obtained by summing the segment values. Vessel tortuosity (VT) was computed by dividing VL by the straight line distance (SLD) between ends of the vessel (VT = VL/SLD). The point of narrowest diameter of the collateral was the anastomosis, or if a

Received May 30, 1984; accepted December 13, 1984. 
vessel narrowing was not evident, the anastomosis was defined as the point one-half the vessel distance between ACA and MCA branch origins. The anastomosis diameter was the internal diameter of the collateral.

\section{STATISTICAL PROCEDURES}

The largest diameter collateral was sampled for estimation of the tortuosity in each of three regions (frontal, parietal, occipital). The three values were averaged to yield one tortuosity value for each hemisphere. One-way analysis of variance (ANOVA) was used for comparisons of mean collateral values (Table 1). Collaterals of MCA interrupted rats were compared with vessels of 10-dayold and 56-day-old unoperated control groups.

\section{RESULTS}

\section{Comparison of 10- and 56-Day-Old Control Rats}

Compared to the 56-day old NW rat, the 10-day-old animal does not have highly differentiated pial surface vessels joining distal rami of the major cerebral arteries (compare Fig. 2A and Fig. 2B). Collaterals in the older animal have greater variation in internal diameter and course. The taper or difference in internal diameter of a collateral and its immediate ACA or MCA supply branch was greater for the 56-day-old control rat than for the

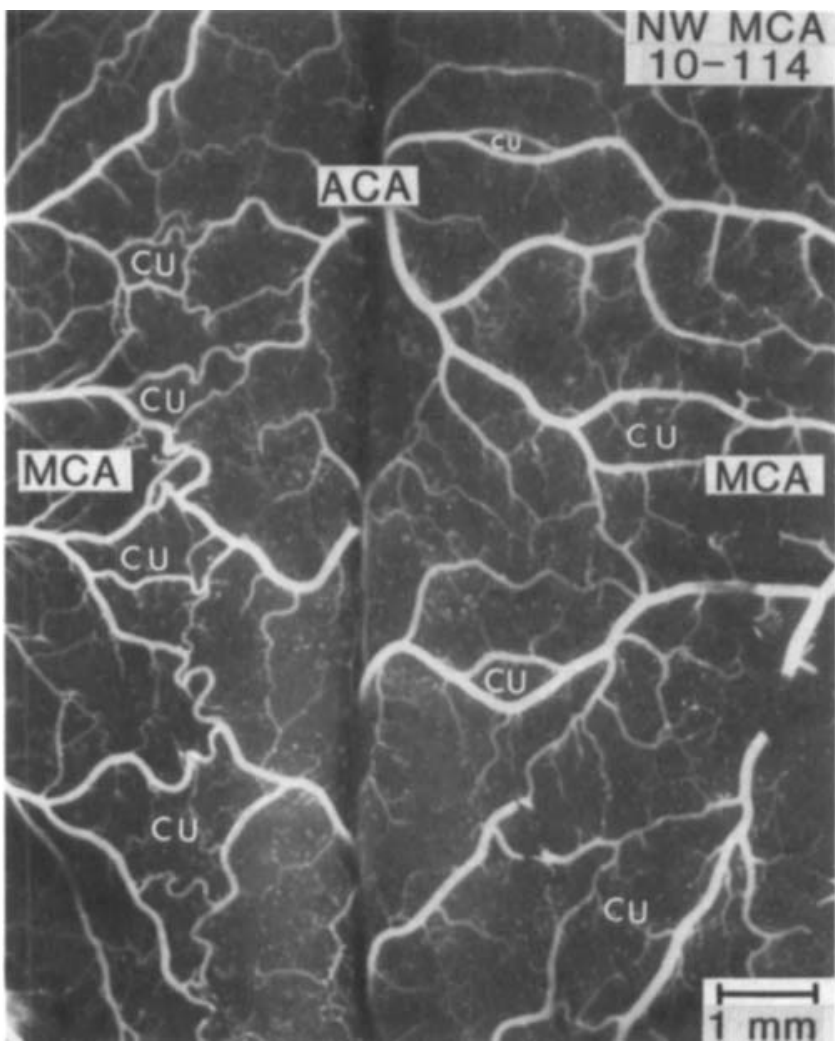

Fig. 1. Dorsal view of the midline region of the brain of a normal Wistar (NW) rat 94 days after interruption of the middle cerebral artery (MCA) on the right experimental side. Papaverine and latex injections were used for visualization of the cerebral arterial vessels Anterior cerebral artery (ACA) rami emerge from the midline and have branch angles facing away from it whereas $\mathrm{MCA}$ branch angles face the midline. ACA and MCA rami anastomose to often form nearly diamond shaped collateral vascular units (CU). Note the tortuosity, diameter, and taper of vessels forming CU on right and left sides. 10-day-old animal (Fig. 2A versus Fig. 2B). Collaterals in the young animal were significantly $(p<0.02$ ) less tortuous in course as compared to collaterals in the older, unoperated controls (Table 1).

\section{Comparison of MCA-Occluded Rats and 10-Day-Old Rats}

Sudden interruption of the MCA in the 10-day-old rat alters the normal pattern of vessel differentiation during the ensuing 46 or 90-110 days. There were significantly ( $p<0.0005$ ) more large-diameter collaterals in MCA interrupted rats compared to 10-day-old controls (Table 1). Right-hemisphere collateral tortuosity 90-110 days after MCA interruption was not significantly ( $\mathrm{p}>$ 0.43 ) different from the tortuosity for either hemisphere of 10-day-old rats (Table 1). In contrast, vessels on the left hemisphere were significantly $(p<0.04)$ more tortuous than the collaterals of either hemisphere of 10 day-old rats (compare left hemisphere Fig. 1 with Fig. $2 \mathrm{~A}$, and examine Table 1 ).

\section{Comparison of MCA-Occluded Rats and 56-Day-Old Control Rats}

In the MCA-interrupted rats, there were significantly ( $p<0.0005$ ) more large-diameter collaterals in comparison with 56-day-old controls (Table 1). There is a char. acteristic taper of rami joining ACA and MCA branches in 56-day-old control animals (Fig. 2B). In animals with right MCA interruption, the collaterals had less taper, compared to vessels on the left hemisphere (Fig. 1) or vessels in the 56-day-old control (Fig. 2C compared to Fig. 2B). Tortuosity of vessels on the right hemisphere was less than the tortuosity of vessels on the left hemisphere (compare right and left sides, Fig. 1). For the group of five rats there was a trend, although not significant, toward smaller mean tortuosity values for the right hemisphere collaterals compared to vessels on the left hemisphere ( $p=0.14$ ) or as compared to vessels of either (left $p=0.08$, right $p=0.07$ ) hemisphere of 56 day-old uninterrupted control animals. The difference in variance among groups was not significant $(p>0.43)$.

\section{DISCUSSION \\ Comparison of 10- and 56-Day-Old Control Rats}

Collaterals that join ACA and MCA rami in 56-dayold rats were more tortuous than the branches in 10 . day-old animals. This is evidence that either the pial surface vessels increased in length during the ensuing 46-day period or that the cortical surface underlying the vessels was reduced in size, or that both occurred. Whereas brains of 56-day-old animals are larger than those of 10-day-old growing pups, the brain surface distance between ACA and MCA ends of a collateral would be expected to increase as the brain becomes larger. The increase in tortuosity supports a concept that the length of a collateral increases more than the increase in brain distance separating its ends. Apparently, these collaterals are longer vessels in older animals. The increase in collateral length is not likely to be artifact due to papaverine hydrochloride, because hemispheric asymmetries in the collaterals exist in rats receiving the drug (compare right and left collaterals of Figure 1).

The collaterals increase in length during development of the neocortical circulation. New cortical capillaries are added at times later than the 10 days of age (Craigie, 1925; Caley and Maxwell, 1971; Rowan and Maxwell, 


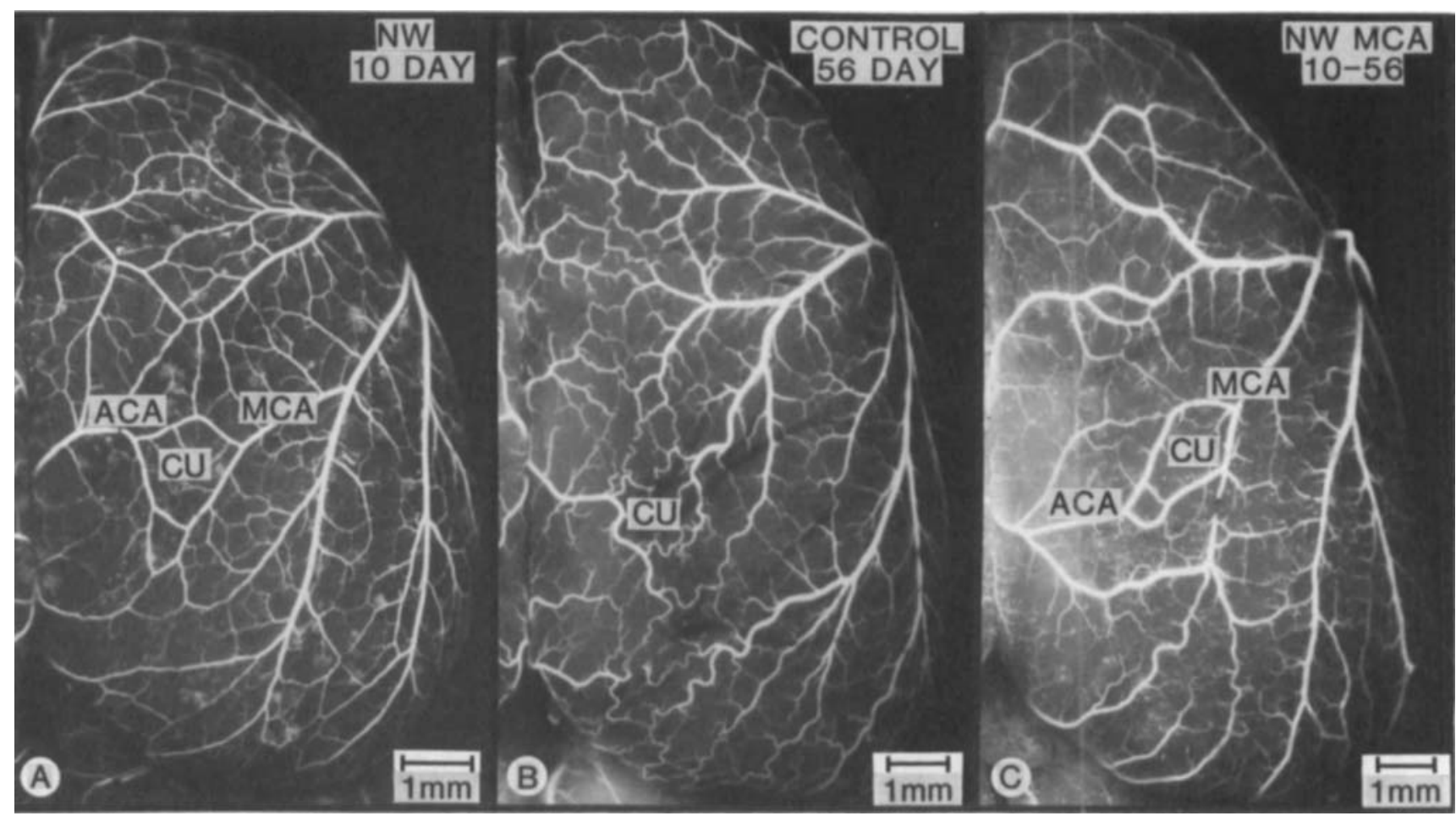

Fig. 2. Dorsal view of the right cerebral hemisphere of three normal Wistar (NW) rats. A, 10-day-old control; B, 56-day-old control; C, 56day-old experimental animal with middle cerebral artery (MCA) inter ruption at age of 10 days. Note that branches of the MCA anastomose extensively with rami of the anterior cerebral artery (ACA) in the

TABLE 1. Rat dorsal cerebral arterial collateral data

\begin{tabular}{|c|c|c|c|c|}
\hline $\begin{array}{l}\text { Rat age } \\
\text { (days) }\end{array}$ & Hemisphere & $\mathbf{n}$ & $\begin{array}{c}\text { Mean } \\
\text { tortuosity } \\
\text { value } \\
\pm \text { S.E.M. }\end{array}$ & $\begin{array}{c}\text { Mean no. } \\
\text { collaterals } \\
\text { with diameter } \\
60-120 \mu \mathrm{m} \\
\pm \text { S.E.M. }\end{array}$ \\
\hline \multicolumn{5}{|l|}{ Control } \\
\hline 10 & left & 5 & $1.16 \pm 0.06$ & $2.6 \pm 0.9$ \\
\hline 10 & right & 5 & $1.15 \pm 0.01^{\mathrm{a}}$ & $3.2 \pm 0.2$ \\
\hline \multicolumn{5}{|l|}{ Control } \\
\hline 56 & left & 5 & $1.36 \pm 0.06^{b}$ & $2.0 \pm 0.6$ \\
\hline 56 & right & $\mathbf{5}$ & $1.36 \pm 0.00^{\mathrm{c}}$ & $2.2 \pm 0.7$ \\
\hline \multicolumn{5}{|c|}{ Right MCA interrupted } \\
\hline $100-120$ & left & 5 & $1.33 \pm 0.06^{\mathrm{d}}$ & $2.8 \pm 0.7$ \\
\hline $100-120$ & right & 5 & $1.21 \pm 0.09^{\mathrm{e}}$ & $6.4 \pm 0.3^{\mathrm{f}}$ \\
\hline
\end{tabular}

${ }^{\mathrm{a}} \mathrm{p}<0.02$ comparison of 10 - and 56 -day-old rats.

$\mathrm{b}_{\mathrm{p}}<0.08$ comparison of 56 - and $100-120$-day-old rats.

$c_{\mathrm{p}}<0.07$ comparison of 56 - and 100-120-day-old rats.

$\mathrm{dp}<0.04$ comparison of 10 - and 100-120-day-old rats

$e_{p}>0.43$ comparison of 10 - and $100-120$-day-old rats.

$\mathrm{f}_{\mathrm{p}}<0.0005$ comparison with any other control group.

1981). Blood supply to newly added capillaries in the cortex must come from pial surface branches, since there is no vascular source for the cortex from within the brain (Van den Bergh, 1969). The primary role of these collaterals is to supply cortical-penetrating side branches in the vascular zone bordering the ACA and MCA tissue fields with blood from either ACA or MCA source, and control rats. The collateral vascular units (CU) are formed by anastomosing branches of the ACA and MCA, respectively. Compare tortuosity, diameter, and taper of the arterioles forming CU in the three specimens.

the length increase may accommodate more branches as the 10-day-old rat develops.

Systemic blood pressure rises as young rats mature, and the pressure rise is associated with increased vascular resistance (Lais and Brody, 1977). Because blood flow is directly proportional to the blood pressure gradient, the 4th power of the radius of a vessel, and inversely proportional to the vessel length (Berne and Levy, 1977), a rise in blood pressure in the young developing rat protects against a reduction of blood flow with increases in length and taper of the vessels. The increase in taper of the collaterals in older control rats compared to younger ones suggests the resistance to collateral blood flow increases with age. As a result of increased vascular resistance in the anastomoses, the collateral blood pressure distal to the anastomoses is lower in old rats compared to young ones. The increased resistance condition presents no vascular supply problem so long as the demand for collateral blood flow is minimal.

\section{Comparison of MCA-Interrupted Rats and Controls}

After the MCA was suddenly interrupted in 10-dayold rats, vascular changes enhanced the collateral circulation. The blood pressure gradient across anastomoses was raised by the occlusion. The higher blood pressure on the non-MCA side of the anastomoses caused blood to flow through the collaterals to protect the MCA tissue from infarction (Coyle, 1982). There were more 
large-diameter collaterals in the MCA-interrupted rats than any one of the control groups. Small-diameter collaterals existing at occlusion time probably become large-diameter ones (Coyle, 1984). The collaterals were less tortuous and thus shorter than vessels in 56-day-old controls. Because blood flow is related to the radius and length of a vessel as noted above, large-diameter, short collaterals promote more flow than small-diameter, long ones.

Compared to 56-day-old control vessels, the finding of shorter collaterals 90-110 days after MCA interruption in 10-day-old animals differs from the finding of even longer collaterals 20 days after MCA occlusion in 36 day-old rats (Coyle, 1984). Because the duration between MCA interruption and experiment termination was about 5 times greater for rats with short collaterals, some factor in addition to the duration of the experiment must determine the observed differences in length. Blood pressure in the collaterals of rats with MCA interruption is greater than the blood pressure in control vessels because blood pressure is greater in larger pial arteries than in smaller ones (Harper and Bohlen, 1984). With a rise in blood pressure, increased stress may stimulate vascular wall thickening (Hart et al., 1980) and attenuate vessel lengthening. With MCA occlusion coming after natural length increases and more branching by 36 days postpartum, the already longer collaterals are not remodeled into straighter, shorter vessels (Coyle, 1984). These collaterals are lengthened even more, possibly in response to stress changes associated with turbulence at branch sites. A length increase could change the angle between a collateral and its branch and thus alter wall stress due to blood flow disturbances.

\section{ACKNOWLEDGMENTS}

The author is grateful to J. Chambers for providing technical assistance with the photography and measurements. Support was provided by NIH grants 18575 and 31468

\section{LITERATURE CITED}

Berne, R.M., and M.N. Levy (1977) Cardiovascular Physiology, 3rd ed, The C.V. Mosby Company, Saint Louis, pp. 53-74.

Caley, D.W., and D.S. Maxwell (1971) Ultrastructure of the developing cerebral cortex in the rat. In: Brain Development and Behavior. M.B. Sterman, D.J. McGinty, and A.M. Adinolti, eds. Academic Press, New York, pp. 91-107.

Coyle, P. (1981) PET interface to BIT PAD. Micro-The 6502/6809 Journal. 38:83-85.

Coyle, P. (1982) Middle cerebral artery occlusion in the young rat. Stroke 13:855-859.

Coyle, P. (1984) Diameter and length changes in cerebral collaterals after middle cerebral artery occlusion in the young rat. Anat. Rec., 210:357-364

Coyle, P., and P.T. Jokelainen (1982) Dorsal cerebral arterial collaterals of the rat. Anat. Rec., 203:397-404.

Coyle, P., and P.T. Jokelainen (1983) Differential outcome to middle cerebral artery occlusion in spontaneously hypertensive strokeprone rats (SHRSP) and Wistar Kyoto (WKY) rats. Stroke, 14:605611.

Coyle, P., Odenheimer, D.J., and C.F. Sing (1984) Cerebral infarction after middle cerebral artery occlusion in progenies of spontaneously stroke-prone and normal rats. Stroke, 15:711-716.

Craigie, E.H. (1925) Postnatal changes in vascularity in the cerebral cortex of the male albino rat. J. Comp. Neurol., 39:301-324.

Craigie, E.H. (1955) Vascular patterns of the developing nervous system. In: Biochemistry of the Developing Nervous System. H. Waelsch, ed. Academic Press, New York, pp. 28-51.

Harper, S.L., and H.G. Bohlen (1984) Microvascular adaptation in cerebral cortex of adult spontaneously hypertensive rats. Hypertension, 6:408-419.

Hart, M.N., Heistad, D.D., and M.J. Brody (1980) Effect of chronic hypertension and sympathetic denervation on wall/lumen ratio of cerebral vessels. Hypertension, 2:419-423.

Jokelainen, P.T., Jokelainen, G.I., and P. Coyle (1982) Non-random distribution of rat pial arterial sphincters. In: Cerebral Blood Flow: Effects of Nerves and Neurotransmitters. D.D. Heistad and M.L. Marcus, eds. Elsevier North Holland, Inc., New York, pp. 107-116.

Lais, L.T., and M.J. Brody (1978) Vasoconstrictor hyperresponsiveness: an early pathogenic mechanism in the spontaneously hypertensive rat. Eur. J. Pharmacol., 47:177-189.

Rowan, R.A., and D.S. Maxwell (1981) Patterns of vascular sprouting in postnatal development of the cerebral cortex of the rat. Am. J. Anat., 160:247-255.

Van den Bergh, R. (1969) The periventricular intracerebral blood supply. In: Research on the Cerebral Circulation, Third International Salzburg Conference. J.S. Meyer, H. Lechner, and O. Eichorn, eds. C.C. Thomas, Springfield, Illinois, pp. 52-65. 